\title{
Housing First for Long-Term Shelter Dwellers with Psychiatric Disabilities in a Suburban County: A Four- Year Study of Housing Access and Retention
}

\author{
Ana Stefancic $\cdot$ Sam Tsemberis
}

Published online: 26 June 2007

(C) Springer Science+Business Media, LLC 2007

\begin{abstract}
Housing First is an effective intervention that ends and prevents homelessness for individuals with severe mental illness and co-occurring addictions. By providing permanent, independent housing without prerequisites for sobriety and treatment, and by offering support services through consumer-driven Assertive Community Treatment teams, Housing First removes some of the major obstacles to obtaining and maintaining housing for consumers who are chronically homeless. In this study, consumers diagnosed with severe mental illness and who had the longest histories of shelter use in a suburban county were randomly assigned to either one of two Housing First programs or to a treatment-as-usual control group. Participants assigned to Housing First were placed in permanent housing at higher rates than the treatment-as-usual group and, over the course of four years, the majority of consumers placed by both Housing First agencies were able to maintain permanent, independent housing. Results also highlight that providers new to Housing First must be aware of ways in which their practices may deviate from the essential features of Housing First, particularly with respect to enrolling eligible consumers on a first-come, first-served basis and separating clinical issues from tenant or housing responsibilities. Finally, other aspects of successfully implementing a Housing First program are discussed.
\end{abstract}

Keywords Housing First · Homelessness · Mental illness · Choice

\footnotetext{
A. Stefancic

Department of Sociomedical Sciences, Columbia University, New York, NY, USA

S. Tsemberis $(\bowtie)$

Pathways to Housing, Inc., 55 W 125th St., 10th Floor, New York, NY 10027, USA

e-mail: tsemberis@pathwaystohousing.org
} 


\section{Introduction}

Housing First is an effective housing and treatment intervention that ends and prevents homelessness for individuals with severe mental illness, co-occurring addictions, and other health problems, who have remained homeless for years (Gulcur et al. 2003; Tsemberis et al. 2004). Although this chronically homeless group constitutes only a minority of the homeless population, these individuals can account for over half of all public shelter stays (Kuhn and Culhane 1998). They also consume costly acute care services, such as emergency medical, substance use, and psychiatric care, often seeking out these services as a temporary respite from homelessness (Folsom et al. 2005; Kuno et al. 2000; McNiel and Binder 2005). By providing permanent, independent housing without prerequisites for sobriety and treatment, Housing First removes significant barriers to housing entry. By offering flexible and comprehensive consumer-driven support services that maximize housing retention, the model also prevents recurrent homelessness.

With an emphasis on funding permanent housing and support services for homeless individuals with disabling conditions, the federal Initiatives to End Chronic Homelessness, launched by the U.S. Interagency Council on Homelessness, is forging a comprehensive federal approach to end homelessness. Housing First programs are central components of these initiatives, as well as those of the more than 200 cities across the United States that have drafted ten-year plans to end chronic homelessness. This study examined the effectiveness of the Housing First approach, as implemented by two different programs in a suburban county, with regard to consumers' housing status and housing retention rates. It also considers the programs' divergent approaches to consumer selection and discharge, and their implications for consumer outcomes.

\section{Traditional Housing and Treatment Services}

Housing First offers a sharp contrast to existing housing programs for persons with mental illness, which typically offer permanent, independent housing only after consumers have demonstrated sobriety, psychiatric stability, and "housing readiness" by graduating through a sequence of short- and long-term treatments and transitional housing arrangements. One of the main reasons individuals remain chronically homeless is the reluctance of these traditional programs to provide housing to consumers who refuse psychiatric treatment, who are actively using alcohol or drugs, or whose histories of behavioral problems or criminal activity have led them to being labeled "not housing ready" (Meschede 2004). Because eligibility for housing is based on an individual's willingness and ability to maintain sobriety, adhere to treatment, and adapt well to living in supervised congregate residences, many homeless persons with disabling conditions do not make an exit from homelessness. Those who do gain entry into housing programs are often evicted back into homelessness due to relapse, violations of program rules, or preference for self-determination and independent living, even if it means returning to the streets (Hopper 2006; Meschede 2004). 


\section{Housing First}

By operating housing services in a manner that is consistent with what consumers identify as their first priority-housing-Housing First engages persons whom traditional supportive housing providers have been unable to engage. Housing First programs offer immediate access to permanent independent housing, without requiring treatment compliance or abstinence from drugs or alcohol. The goals of Housing First are not only to end homelessness, but also to promote consumer choice, recovery, and community integration. Thus, Housing First programs offer housing in the form of scatter-site independent apartments in buildings rented from private landlords. Such residential arrangements honor the preference of consumers for apartments of their own (Goldfinger and Schutt 1996; Tanzman 1993) and afford people with psychiatric disabilities the opportunity to live in the community virtually indistinguishable from other residents, a fundamental aspect of recovery (Harding 1987a, b). To maintain this integration, the program does not lease more than $15 \%$ of the units in any one building. Units are rented from private landlords. This immediate offer of an independent apartment is a very powerful tool of engagement and consumers begin to recognize that the program is responsive to their needs and preferences. Addressing the consumer's needs first is the guiding principle for all subsequent services that are offered and is the foundation for building trusting and supportive clinical relationships, an essential component of Housing First that maximizes housing retention.

Although limited community resources and funding may titrate the intensity and breadth of treatment and support services that Housing First programs may provide, ideally, consumers will have access to integrated and comprehensive support, usually through multi-disciplinary Assertive Community Treatment (ACT) teams, with slight modifications (Stein and Santos 1998). ACT teams are located off-site, but are on-call 24 hours a day, 7 days a week, and provide most services in a client's natural environment (e.g., apartment, workplace, neighborhood) on a time-unlimited basis. Consumers are not discouraged, however, from visiting team members in their office. Teams are staffed with social workers, nurses, psychiatrists, and specialists in supported employment and peer counseling, and meet the national evidence-based practice standards for ACT (Phillips et al. 2001). Teams use a recovery-oriented practice philosophy that includes consumer choice as well as a harm reduction approach to substance use and mental health treatment. Teams offer consumers assistance with issues including housing, health care, medication, employment, family relations, and recreational opportunities (Tsemberis and Asmussen 1999). Service plans are not based on clinician assessments of consumers' needs; rather individual consumers choose the type, sequence, and frequency of services and have the option of refusing formal treatment altogether without compromising their housing. Such a flexible, consumer-driven approach to clinical practice helps ensure that consumers remain engaged with the team, particularly during crisis, and facilitates open rapport.

Though consumers can refuse formal clinical services, such as taking psychiatric medication, seeing a psychiatrist, or working with a substance use specialist, the programs have requirements for a minimum of one visit per week by the team. The 
main purpose of the periodic apartment visits are to assure tenants' safety and wellbeing, to assess the condition of their apartment, and most importantly to keep open the channels of communication between the consumer and members of the team. A typical visit consists of observing the consumer's mental and physical state, following up on outstanding issues from the last visit, and offering assistance with any domain the consumer wishes to address, from apartment repairs to visiting families. The visits provide two essential forms of support: instrumental and emotional. The team often helps out with routine chores, but perhaps more importantly conveys to the consumer that he or she matters to the team. The team may just 'sit and chat' for a while but through it all they are empathic, compassionate, and purveyors of hope.

Consumers have their own lease or sublease and have the same rights of tenancy as other residents in their buildings. As tenants, consumers remain housed as long as they meet the obligations of a standard lease. As in most supportive housing programs, consumer have an obligation to pay $30 \%$ of their income towards rent (typically, 30\% of their Supplemental Security Income). Further, by separating the criteria for housing from treatment, Housing First programs prevent reentry into homelessness for this high-risk group. The adverse consequences of relapse into substance abuse or a psychiatric crisis are mitigated because relapse is addressed by providing intensive treatment or facilitating admission to detox or hospital to address the clinical crisis - not by eviction because the consumer is using or experiencing psychotic symptoms. After completing treatment for their clinical conditions, consumers return to their apartments. Consumers in Housing First programs only risk eviction from their apartments for the same reasons as other building tenants including nonpayment of rent, creating unacceptable disturbances to neighbors, or for other violations of a standard lease. To prevent such evictions, teams work closely with consumers and landlords to address potential problems in the early stages.

Initial evaluations of Housing First in urban areas with primarily street-dwelling samples have yielded dramatically successful results. In one randomized clinical trial of housing alternatives over a four year period, individuals assigned to Housing First spent significantly less time homeless, more time in stable housing, and accrued fewer costs in terms of residential stays as compared to consumers in more traditional housing programs (Gulcur et al. 2003; Tsemberis et al. 2004). Additionally, although consumers in traditional programs reported higher rates of substance use treatment, there were no significant differences in rates of alcohol or substance use between the two groups (Padgett et al.2006). Further, consumer choice, an essential component of Housing First, has been associated with decreased psychiatric symptomatology, a relationship that is partially mediated by perceived sense of personal control or mastery (Greenwood et al. 2005). Finally, consumers rated housing satisfaction significantly higher when living in more independent supported housing settings as compared to congregate or community residences (Siegel et al. 2006). The study reported here explores whether the Housing First approach can achieve similar high levels of residential stability with a sample of chronic shelter users with psychiatric disabilities in a suburban county. Additionally, it identifies issues that may arise when the Housing First intervention is 
implemented by an agency that has previously practiced the traditional "housing readiness" approach to housing and treatment for the population.

\section{Study Objectives}

In the early months of 2000, a County Department of Social Services (DSS) contracted two organizations to provide Housing First services to consumers with psychiatric disabilities, and often co-occurring substance abuse disorders, who were chronic recidivists in the county's homeless shelter system. One provider was an agency with a long established record of operating Housing First programs but new to the county (Pathways to Housing); the other was a newly formed Consortium of treatment and housing agencies from within the county but with no prior experience operating Housing First. The study randomly assigned shelter users to one of the two Housing First programs as well as a "treatment as usual" control group. The housing status of participants in all three groups is presented at the 20-month follow-up point and housing retention rates for the two Housing First groups through just under four years. Additionally, because the goals of Housing First are to screen-in those clients considered "difficult to house," and to accept everyone from this targeted group who meets eligibility criteria on a first-come, first-served basis, we present data on the proportion of consumers outreached/engaged versus actually housed. We also discuss how the engagement and retention data suggest that the Housing First agencies may have taken different approaches to housing placement and discharge. Finally, in order to address the cost-effectiveness of the Housing First approach, we present the contractual per/client costs that were associated with each program.

\section{Method}

\section{Procedures}

Pathways to Housing (Pathways) and a Consortium of local agencies (Consortium) were contracted by the county to provide Housing First services, in the form of independent scatter-site apartments and ACT, to chronic shelter users with psychiatric disabilities. Each program was expected to house 60 individuals. The control group received the county's usual array of services that included shelterbased programs and transitional housing.

Data were collected from administrative records maintained by the Department of Social Services as well as the respective Housing First agencies. Each month, the two Housing First agencies submitted reports to the Department of Social Services indicating the number of consumers whom they had outreached/engaged, the number of consumers currently remaining in housing, and the number of consumers no longer housed. Residential data for Housing First consumers were available continuously for just under four years (47 months). Residential data for control participants were obtained through the county's computerized shelter tracking system, but were only available at the 20 -month time-point. Because data were not 
available for all three groups throughout the study follow-up period, two types of housing outcomes are presented. The first outcome, housing status, was a single point-in-time count of the number of persons housed within the two Housing First groups and the control group at 20 months. The second outcome, housing retention, consisted of housing retention rates for the two Housing First groups for a period of 47 months. Rates of housing retention were calculated each month by dividing the number of consumers still maintaining housing by the number of consumers ever housed by the agency (currently in housing/ever housed). Finally, data are presented regarding the number of participants outreached/engaged and housed by each Housing First agency every month through 47 months. Staff at each agency conducted outreach by contacting participants and conducting their agency's intake assessment to determine participants' eligibility for entry into the Housing First program. Participants who had completed these assessments or were in the process of being scheduled for assessment, were counted as outreached/engaged. With the assistance of the county's DSS, each Housing First agency attempted to contact consumers who were randomly assigned to them by proceeding sequentially along their list and completing assessment interviews with potential consumers. However, not all consumers who completed this assessment were enrolled into the program and received housing. Only participants whom the agencies accepted and housed continued to receive Housing First treatment services.

\section{Sample}

Participant eligibility criteria for entry into the study included a diagnosis of severe mental illness and chronic shelter use. The county referred individuals with the longest histories of shelter use and with the most frequent interruptions in stay. Individuals were identified as having a psychiatric disability as a result of mental illness-based eligibility (Axis I diagnosis) for Supplemental Security Income (SSI) benefits. Persons diagnosed with a co-occurring substance use disorder were also eligible. Shelter residents who were under 18 , diagnosed primarily with a developmental disability, or residing in the family shelter system were ineligible. In early 2001, a total of 260 clients were originally selected for the project from the county's DSS emergency shelter system and randomly assigned to one of three groups as follows: 105 to Pathways, 104 to the Consortium, and 51 to control. By the end of 2001, 52 additional consumers were referred to the project in a second round of assignment, increasing the numbers for Pathways and Consortium to 131 and 130, respectively, while the control remained at 51 . Subsequently, approximately 80 additional participants were assigned to the Consortium throughout the course of the project.

As Table 1 indicates, the three groups as originally assigned (260 participants) were similar in terms of demographic characteristics and presence of psychiatric disorders. There were no significant differences among the groups in terms of sex, race, and alcohol use. Pathways participants had higher rates of current drug use or dependence $\left(\chi^{2}=10.56, P=.032\right)$ and tended to have higher rates of psychotic disorders $\left(\chi^{2}=14.15, P=.093\right)$. As a whole, the sample was similar to other populations of shelter users with psychiatric disabilities studied elsewhere (Hopper et al. 1997; Kuhn and Culhane 1998). 
Table 1 Demographics, psychiatric diagnoses, and substance abuse disorders of originally assigned groups $^{\mathrm{a}}$

\begin{tabular}{|c|c|c|c|c|c|c|}
\hline & \multicolumn{2}{|c|}{ Pathways $(n=105)$} & \multicolumn{2}{|c|}{ Consortium $(n=104)$} & \multicolumn{2}{|c|}{ Control $(n=51)$} \\
\hline & $N$ & $\%$ & $N$ & $\%$ & $N$ & $\%$ \\
\hline \multicolumn{7}{|l|}{ Sex } \\
\hline Male & 71 & 67.6 & 83 & 79.8 & 39 & 76.5 \\
\hline Female & 34 & 32.4 & 21 & 20.2 & 12 & 23.5 \\
\hline \multicolumn{7}{|l|}{ Race } \\
\hline African-American & 63 & 60 & 56 & 53.8 & 28 & 54.9 \\
\hline Hispanic & 8 & 7.6 & 13 & 12.5 & 7 & 13.7 \\
\hline Caucasian & 30 & 28.6 & 29 & 27.9 & 14 & 27.5 \\
\hline Other & 1 & 0.9 & 2 & 1.9 & 0 & 0 \\
\hline Unreported & 3 & 2.9 & 4 & 3.9 & 2 & 3.9 \\
\hline \multicolumn{7}{|l|}{ Alcohol } \\
\hline Dependence/Abuse & 48 & 45.7 & 36 & 34.6 & 21 & 41.2 \\
\hline Dependence/Abuse in Remission & 9 & 8.6 & 18 & 17.3 & 8 & 15.7 \\
\hline Unspecified & 0 & 0 & 3 & 0 & 5 & 9.8 \\
\hline \multicolumn{7}{|l|}{ Drug } \\
\hline Dependence/Abuse & 54 & 51.4 & 33 & 31.7 & 20 & 39.2 \\
\hline Dependence/Abuse in Remission & 8 & 7.6 & 19 & 18.3 & 8 & 15.7 \\
\hline Unspecified & 3 & 2.9 & 3 & 2.9 & 3 & 5.9 \\
\hline \multicolumn{7}{|l|}{ Mental Illness } \\
\hline Schizophrenia & 48 & 45.7 & 45 & 43.3 & 16 & 31.4 \\
\hline Major Depressive Disorder & 12 & 11.4 & 15 & 14.4 & 6 & 11.8 \\
\hline Bipolar Disorder & 19 & 18.1 & 18 & 17.3 & 12 & 23.5 \\
\hline Shizoaffective Disorder & 11 & 10.5 & 2 & 1.9 & 2 & 3.9 \\
\hline Other & 10 & 9.5 & 15 & 14.4 & 11 & 21.6 \\
\hline Information unavailable & 5 & 4.8 & 9 & 8.7 & 4 & 7.8 \\
\hline
\end{tabular}

a Demographic characteristics were not available for participants who were randomly assigned to Housing First in the second and third rounds of the project

It was the responsibility of each agency to contact and engage participants once they received the list of consumers that were randomly assigned to them. The agencies could, therefore, conduct outreach and accept consumers from the list at their discretion. Additionally, because enrollment into the Housing First programs was staggered, participants entered into housing at various stages of the program's existence.

\section{Results}

\section{Housing Status}

Pathways housed its first consumer in early June of 2000 and the Consortium housed its first consumer the following month. Twenty months later, by February 2002, 
Pathways had placed a total of 62 clients in independent scatter-site housing, at an average rate of approximately 3.1 clients per month. Five of these clients were discharged from the program (four moved out of state), leaving 57 still housed at the end of 20 months. During this same time period, the Consortium had housed 52 clients, at an average rate of approximately 2.6 clients per month. Six of these clients were discharged from housing, leaving 46 consumers still housed at the end of 20 months. Altogether, the Housing First agencies had 103 participants in permanent housing at this time.

In contrast to the participants enrolled in Housing First, few participants in the control group were living in permanent housing by the end of the 20 -month period. Twelve were placed into supportive housing by the Department of Mental Health (DMH) and one was placed by the Veteran's Administration (VA). Two consumers reconnected with their children and were transferred to the county's Homeless Families System. They were placed into emergency housing units operated by a non-profit agency contracted by the county. Only one client was living independently, and another moved in with a family member. Five clients remained in shelters and three ended up in a variety of institutional settings. One client was deemed ineligible for $\mathrm{DMH}$ placement due to a developmental disability and four moved out of the county. The whereabouts of the remaining 21 participants who dropped out of the shelter system were unknown. Additionally, members of the control group continued to cycle in and out of the system over the course of the study period. For control group members with available shelter histories during the 20 months, the average number of returns to the shelter was 3.6 and the average length of those returns was 13.3 nights.

\section{Housing Retention}

Figure 1 presents housing retention rates by Housing First condition for each month for a period of 47-months. Two years after program inception, approximately $84 \%$ of the consumers who had been housed by the Housing First agencies were still in housing, with Pathways at $88.5 \%$ and the Consortium at $79 \%$. After 47 months, approximately $68 \%$ of consumers housed by Housing First were still maintaining housing, with Pathways at $78.3 \%$ and the Consortium at $57 \%$.

\section{Selection: Engaged vs. Housed}

Figure 2 presents the number of participants in housing within each Housing First agency for each month and the total number of participants that the agency had outreached/engaged. Two years after program inception, Pathways had 54 participants in housing out of the 78 participants that they had outreached/ engaged. At this same time-point, the Consortium had 54 participants in housing out of the 164 that they had outreached/engaged. By the end of 47 months, Pathways had 58 participants in housing out of the 89 participants engaged and the Consortium had 48 participants in housing out of the 204 that they had outreached/engaged. 


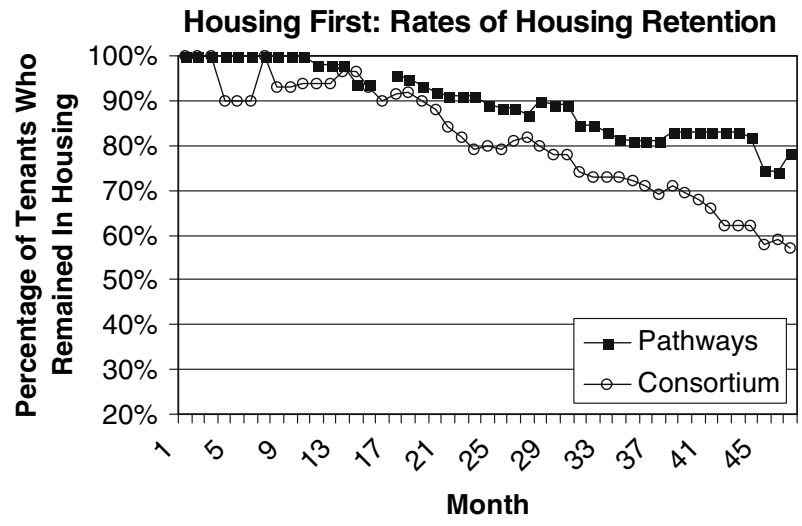

Fig. 1 Housing First: rates of housing retention

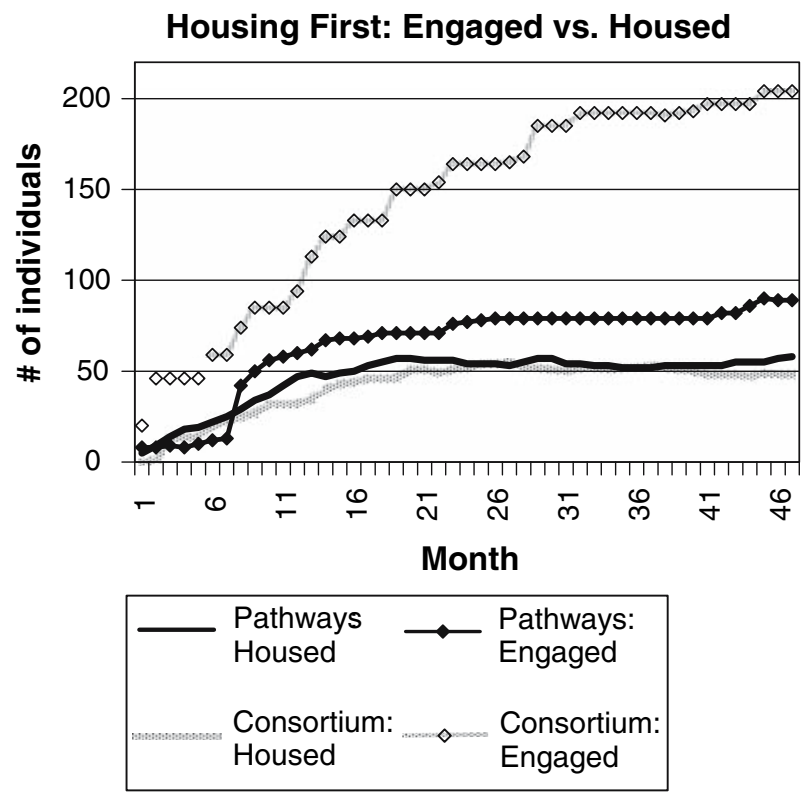

Fig. 2 Housing First: engaged/outreached versus housed

Cost

As Table 2 indicates, the per diem costs for Pathways and the Consortium, based on 2002 budgets, was $\$ 55.92$, or $\$ 20,410$ per client per year. Shelter reimbursement rates, meanwhile, ranged from a $\$ 66.49$ to $\$ 119.26$ per diem, or $\$ 24,269$ to $\$ 43,530$ per client per year. The Housing First costs included: staff salaries, operation costs, and funding for rents and property management. 
Table 2 Annual and per diem costs for supported housing and shelters in the county

\begin{tabular}{lll}
\hline & Per diem cost & Annual cost per client \\
\hline Supported Housing (120) & $\$ 55.92$ & $\$ 20,410$ \\
Pathways (60) & $\$ 51.64$ & $\$ 18,850$ \\
Consortium (60) & $\$ 60.19$ & $\$ 21,971$ \\
Shelters & $\$ 66.49-\$ 119.26$ & $\$ 24,269-43,530$ \\
\hline
\end{tabular}

\section{Discussion}

This report provides preliminary outcomes from a suburban county's Housing First implementation project, the goal of which was to reduce homelessness for the county's chronically homeless population. Almost two years after Housing First was introduced into the county, results indicate that participants assigned to Housing First were placed in permanent housing at higher rates than the treatment-as-usual group, who had received the county's standard array of services. Twenty months was a long enough period of time for participants in the control group to have successfully advanced along the continuum through treatment and transitional housing to reach permanent, independent housing. However, the data do not demonstrate such progress, revealing instead that most participants in the control group still had not reached the endpoint of permanent, independent housing. Meanwhile, housing retention rates show that the majority of clients in both Housing First agencies were able to end years of homelessness and were assisted in preventing a return to homelessness. Over the course of almost four years, $68 \%$ of participants who entered housing through Housing First were able to keep it without having to satisfy requirements for treatment and sobriety. Pathways' retention rate after four years, which was just below $80 \%$, is noteworthy, especially given the sample's chronic homelessness and high rates of shelter recidivism and cooccurring substance use disorder. As compared to Pathways-an agency with several years of experience providing Housing First services-the lower rate of housing retention for the Consortium agencies may be reflective of some of the challenges that existing providers face when shifting their services towards Housing First.

Implementation of a Housing First approach in new locales and within existing agencies can encounter significant barriers. Such implementation difficulties were reported by Felton (2003) who documented the experiences of key stakeholders during the implementation of this "Housing First" intervention in the county. Housing First challenges traditional provider-consumer relationships by requiring clinicians and other service providers to relinquish authority in prioritizing consumers' needs and goals. Further, it requires them to shift perspectives from an emphasis on mental health and substance use needs towards a greater appreciation of the housing needs of consumers (Meschede 2004). It requires providers to reconsider their beliefs about the capabilities of formerly homeless persons with mental illness, particularly with regard to their ability to maintain independent housing when offered comprehensive, but flexible, supports. 
Additionally, existing agencies and providers may be ill-prepared for the programmatic and systemic changes implied by adopting a Housing First approach that greatly reduces the need for shelters or other transitional housing programs. These providers may have very practical concerns, such as losing valuable shelter contracts, and by extension, jobs for shelter staff.

Providers new to Housing First must also be aware of ways in which their practices may deviate from some of the essential features and philosophy of Housing First. The Consortium's lower retention rate suggests that their discharge policies may not reflect the practice of separating housing from treatment. It is important to continue to provide services through housing loss and to assist consumers in finding new housing when they experience difficulties in one building or neighborhood, or upon their discharge from hospital or clinic-based treatment. Providers shifting to Housing First services must, therefore, be especially observant of the need to keep clinical matters separate from housing matters and to ensure that a clinical crisis results in the consumer receiving intensive clinical services, not being evicted from housing.

The disparity between the Housing First programs in the ratio of clients housed to those outreached/engaged suggests that the agencies used two different approaches to enrolling participants and placing them in housing. The large number of participants engaged by the Consortium may suggest that these agencies were extremely rigorous in their efforts to screen-out ineligible applicants. Also possible, however, is that the Consortium's selective enrollment was the result of clinicians turning down participants who were eligible but whom they did not consider appropriate for immediate placement in permanent housing. New Housing First providers may still be reluctant to work with consumers who are traditionally considered "difficult to house." One of the principles of Housing First is to target consumers who have had difficulty accessing traditional services and to then sequentially accept these consumers on a first-come, first-served basis. Providers who are shifting towards Housing First services must, therefore, be mindful of a long held but erroneous bias that equates psychiatric symptoms or substance use with an inability to maintain housing. Given that the Consortium had lower rates of housing retention despite carrying out a more extensive selection of consumers also reinforces the fact that housing providers and clinicians are not able to successfully predict which consumers among a chronically homeless pool of applicants will be able to successfully maintain housing.

With regard to implementing a Housing First approach based on a scattered-site, community integration model in a suburban or rural locale, service providers may encounter several challenges that could require slight modifications to the model. With regard to staffing, if sufficient resources for a full-scale ACT team operating within one agency are lacking, or if the number of consumers to be served is small, programs can create smaller sub-ACT teams that maintain low caseload ratios but must broker some services from agency or community providers. Another variant successfully implemented in some cities consists of 'composite teams' comprised of several staff members but each from a different agency (e.g., a mental health expert from the local mental health clinic, a substance abuse specialist from the drug treatment program, and a case worker from the shelter). Programs may also employ 
intensive case managers who provide essential supports to consumers and then broker other specialty services. Housing First staff working in suburban or rural areas must also traverse greater distances to visit consumers. Staffing patterns may shift in order to address this issue: for example, teams may need more staff or teams may need to be redundant with regard to staff with essential specialties, such as nursing. This would require greater financial resources for staff and consumer travel, purchase of extra vehicles, additional staff, or reimbursing staff for use of their personal vehicles.

With regard to housing stock, affordable housing may be in more limited supply in non-urban areas and studio or one-bedroom apartments may be in short supply. In these areas consumer choice may be restricted to the limited options available and consumers may have to choose between renting a room in someone's home, sharing a house with one or two other consumers, or waiting until an individual unit is found. Additionally, rural and suburban areas do not offer the same level of anonymity to consumers as do urban areas, but they may be advantageous in countering the loneliness and alienation that some consumers experience living alone in large cities (Yanos et al. 2004). Finding the right type of affordable housing in non-urban areas, therefore, may be more difficult and time-consuming, requiring greater up-front efforts and investment in securing apartments and other options for potential consumers, as well as implementing an effective public relations and education campaign about the program for community members and key stakeholders. Although tight housing markets or lengthy distances for staff to travel may spur some programs to consider placing consumers in shared or congregate settings, it is important to note that, unless such arrangements are explicitly based on the consumer's preference, they represent a significant deviation from the Housing First model. Housing First programs are successful because they offer consumer-driven solutions to end homelessness, and in most cases, consumer choice dictates provision of scatter-site independent apartments, an approach to ending homeless that is also consistent with broader goals of promoting integration and recovery.

The study reported outcomes through just fewer than four years for participants randomly assigned to Housing First, and included a treatment-as-usual control group at the 20-month time point. Such longitudinal outcomes are uncommon among studies of formerly homeless persons. Additionally, two different programs were implementing the Housing First approach, allowing for a comparison of the number of persons engaged and the housing retention rates. Discrepancies between the programs suggest that the agencies were not operating under all of the same procedures for enrollment and discharge, two areas in which the Housing First approach makes critical departures from traditional programs. Enrollment of targeted chronically homeless individuals with serious mental illness on a firstcome, first-served basis and providing services through housing loss or housing transitions are fundamental aspects of Housing First. It is essential to ensure that agencies adopting a Housing First approach implement it in the form in which it has demonstrated the greatest effectiveness. The study sample was comprised of individuals who were chronically homeless, had severe mental illness, and did not benefit from traditional services. The high rates of co-occurring disorders among 
this sample further confirm that Housing First approaches can be successful with persons who experience multiple impairments.

Nevertheless, the study also has considerable weaknesses. First, demographic data were only available for the first cohort of participants who enrolled into the study and so we cannot accurately describe the entire study sample. Second, despite employing random assignment, not all participants were enrolled by their respective Housing First agency. Though the initial groups were roughly equivalent after random assignment, unfortunately, individual-level data were not available to compare those who were actually housed within each study condition. Consequently, it was not possible to determine how comparable the groups of participants were who actually received housing. Further, the absence of such data made it impossible to determine whether there were any significant demographic differences between those who were housed and not housed within each condition. We cannot, therefore, identify the characteristics that are associated with entry into housing for each condition and across the sample as a whole. Further, almost half of the control participants' whereabouts were unknown at time of follow-up, resulting in substantial amounts of missing data. This weakens our ability to estimate the relative strength of the Housing First approach as compared to the usual sequence of services. Limited resources also did not permit continued follow-up of the control group over the entire 47-month study period. Though unlikely, it is impossible to determine whether the control group caught up with or exceeded the rates of permanent, independent housing reported here for the two Housing First groups after four years.

A final limitation is that the impact of specific agency support and treatment services that were received by participants and their role in maximizing housing retention, were not examined. Because both agencies were funded under the same mechanism, they were very similar in terms of their ACT teams' organizational structure, staffing, and general practices. Given the disparities in housing retention and selection outcomes across agencies, these structural similarities accentuate the potential impact that overarching agency philosophies and more informal, daily team support services may have on consumer outcomes. For example, the Consortium's affiliation with a medical center may have resulted in their ACT team having a lower threshold of tolerance for psychiatric symptoms and/or substance use among their clients. Such a service perspective may have led to greater residential instability if consumers were more abruptly removed from housing and their engagement with the team threatened by having their ability to exercise choice more restricted. Unfortunately, the current study was not able to examine these potential philosophical and services discrepancies between agencies in-depth.

Overall, Housing First has proven to be an effective and less costly alternative for housing chronically homeless individuals with psychiatric disabilities. This study demonstrates that the Housing First approach is effective in the long-term in reducing homelessness and can be successfully implemented in suburban areas and with populations of chronically homeless shelter users with multiple disorders. Other Housing First replication sites also report housing retention rates of $80 \%$ or better through 12-18 months (D. Dunbeck, personal communication, December 
2006). Officials in the county described here have corroborated the positive outcomes. With Housing First as a vital component of the county's overall approach to ending homelessness, it was recently reported that the county had reduced homelessness by two-thirds over a period of approximately five years and was considering "a top-to-bottom shift to the Housing First model" (Scharfenberg 2006). Considering that certain modifications may need to be made to the Housing First model in order to adapt the program to non-urban locales, it is imperative to understand which adjustments are effective and acceptable, and which changes represent unacceptable departures from the model's standard operation and philosophy, and result in poorer client outcomes. Essential to shifting services, in this county and elsewhere, will be to clearly articulate the principles and philosophy of Housing First. To guide program development and to ensure that providers are indeed implementing a Housing First model, it is necessary to develop valid measures that will assess fidelity to Housing First, differentiate it from other models, and further identify the essential ingredients that are associated with positive outcomes. Given the research to date, Housing First holds promise for ending and preventing homelessness and promoting community integration and recovery.

Acknowledgement We give much thanks to John Jost, Ph.D. for his invaluable assistance with data collection and project development.

\section{References}

Felton, B. J. (2003). Innovation and implementation in mental health services for homeless adults: a case study. Community Mental Health Journal, 39(4), 309-322.

Folsom, D. P., Hawthorne, W., Lindamer, L., Gilmer, T., Bailey, A., Golshan, S., et al. (2005). Prevalence and risk factors for homelessness and utilization of mental health services among 10,340 patients with serious mental illness in a large public mental health system. American Journal of Psychiatry, 162(2), 370-376.

Goldfinger, S. M., \& Schutt, R. K. (1996). Comparison of clinicians' housing recommendations and preferences of homeless mentally ill Persons. Psychiatric Services, 47(4), 413-415.

Greenwood, R., Schaefer-McDaniel, N., Winkel, G., \& Tsemberis, S. (2005). Decreasing psychiatric symptoms by increasing choice in services for adults with histories of homelessness. American Journal of Community Psychology, 16, 223-238.

Gulcur, L., Stefancic, A., Shinn, M., Tsemberis, S., \& Fischer, S. N. (2003) Housing, hospitalization, and cost outcomes for homeless individuals with psychiatric disabilities participating in Continuum of Care and Housing First programmes. Journal of Community \& Applied Social Psychology, 13, 171186.

Harding, C. (1987a). The Vermont longitudinal study of persons with mental illness I. American Journal of Psychiatry, 144, 718-726.

Harding, C. (1987b). The Vermont study of persons with mental illness II. American Journal of Psychiatry, 144, 727-735.

Hopper, K. (2006). Redistribution and its discontents: on the prospects of committed work in public mental health and like settings. Human Organization, 65(2), 218-226.

Hopper, K., Jost, J., Hay, T., Welber, S., \& Haugland, G. (1997). Homelessness, mental illness and the institutional circuit. Psychiatric Services, 48(5), 659-665.

Kuhn, R., \& Culhane, D. (1998). Applying cluster analysis to test a typology of homelessness by pattern of shelter utilization: Results from the analysis of administrative data. American Journal of Community Psychology, 26(2), 207-232. 
Kuno, E., Rothbard, A. B., Averyt, J., \& Culhane, D. (2000). Homelessness among persons with serious mental illness in an enhanced community-based mental health system. Psychiatric Services, 51(8), 1012-1016.

McNiel, D. E., \& Binder, R. L. (2005). Psychiatric emergency service use and homelessness, mental disorder, and violence. Psychiatric Services, 56(6), 699-704.

Meschede, T. (2004). Bridges and barriers to housing for chronically homeless street dwellers: The effects of medical and substance abuse services on housing attainment. Retrieved February 14, 2007, from http://www.mccormack.umb.edu/csp/publications/bridgesandbarriers.pdf.

Padgett, D., Gulcur, L., \& Tsemberis, S. (2006). Housing First services for people who are homeless, with co-occurring mental illness and substance abuse. Research On Social Work Practice, 16(1), 74-83.

Phillips, S. D., Burns, B. J., Edgar, E. R., Mueser, K. T., Linkins, K. W., Rosenheck, R., et al. (2001). Moving assertive community treatment into standard practice. Psychiatric Services, 52(6), 771-779.

Scharfenberg, D. (2006, February 26). Homelessness, Halved. The New York Times, Sec. 14WC, p. 1.

Siegel, C. E., Samuels, J., Tang, D., Berg, I., Jones, K., \& Hopper, K. (2006). Tenant outcomes in supported housing and community residences in New York City. Psychiatric Services, 57(7), 982991.

Stein, L. I., \& Santos, A. B. (1998). Assertive community treatment of persons with severe mental illness. New York: Norton.

Tanzman, B. (1993). An overview of surveys on mental health consumers' preferences for housing and support services. Hospital and Community Psychiatry, 44, 450-455.

Tsemberis, S., \& Asmussen, S. (1999). From streets to homes: An innovative approach to supported housing for homeless adults with psychiatric disabilities. Journal of Community Psychology, 27(2), $225-241$.

Tsemberis, S., Gulcur, L., \& Nakae, M. (2004). Housing First, consumer choice, and harm reduction for homeless individuals with a dual diagnosis. American Journal of Public Health, 94, 651-656.

Yanos, P., Barrow, S., \& Tsemberis, S. (2004). Community integration in the early phase of housing among homeless persons diagnosed with severe mental illness: successes and challenges. Community Mental Health Journal, 40(2), 133-150. 